\title{
AGRICULTURA FAMILIAR E O PROGRAMA NACIONAL DE ALIMENTAÇÃO ESCOLAR: CONTEXTO CATARINENSE
}

\author{
FAMILY FARMING AND THE BRAZILIAN NATIONAL SCHOOL FEEDING \\ PROGRAM: CONTEXT OF SANTA CATARINA
}

\section{LA AGRICULTURA FAMILIAR Y EL PROGRAMA NACIONAL DE ALIMENTACIÓN ESCOLAR: CONTEXTO DE SANTA CATARINA}

\author{
Roberta Lamonatto Taglietti ${ }^{1}$ \\ https://orcid.org/0000-0002-3814-6326 \\ Carla Rosane Paz Arruda Teo2 \\ https://orcid.org/0000-0002-1534-6261 \\ Gisele Assumpção Vieira3 \\ https://orcid.org/0000-0002-1866-656X \\ Junir Antônio Lutinski ${ }^{4}$ \\ https://orcid.org/0000-0003-0149-5415
}

Submissão: 18/07/2021 / Aceito: 18/10/2021 / Publicado: 04/02/2022.

\begin{abstract}
Resumo
O objetivo deste trabalho foi contextualizar a agricultura familiar e a sua vinculação ao Programa Nacional de Alimentação Escolar no estado de Santa Catarina no período de 2012 a 2017. Para isso, foi desenvolvido um estudo do tipo analítico de base documental, desenvolvido em uma perspectiva longitudinal retrospectiva. Foi utilizado como fonte de dados os editais de chamadas públicas para aquisição de alimentos da agricultura familiar para a alimentação escolar e, de forma complementar, a partir do Censo Escolar, os relatórios relativos ao número de alunos matriculados na rede de ensino públicas dos municípios que publicaram editais, indicadores socioeconômicos e demográficos dos municípios de Santa Catarina e do Censo Agropecuário Brasileiro. Foram analisados 821 editais de chamada pública, publicadas por 231 municípios catarinenses, que predominantemente são classificados como de pequeno porte. Quando o porte foi associado com indicadores de qualidade da aquisição, como o per capita de alimento saudável representado por frutas, hortaliças e leguminosas constatou-se que os municípios de pequeno porte compraram 46,57\% mais alimentos saudáveis do que os de grande porte no último triênio. Sobre o percentual de aquisição de alimentos da agricultura familiar, observou-se que, a partir de 2014, ocorreu um aumento significativo na média de aquisição. Conhecendo as características do estado e sua
\end{abstract}

\footnotetext{
${ }^{1}$ Doutora em Ciências da Saúde; Docente do Curso de Nutrição. Escola de Saúde. Universidade Comunitária da Região de Chapecó (Unochapecó); E-mail: rotagli@unochapeco.edu.br

2 Doutora em Ciência de Alimentos; Docente do Programa de Pós-Graduação em Ciências da Saúde (PPGCS). Escola de Saúde. Universidade Comunitária da Região de Chapecó (Unochapecó); E-mail:carlateo@ unochapeco.edu.br 3Mestre em Ciências da Saúde pelo Programa de Pós-Graduação em Ciências da Saúde (PPGCS). Universidade Comunitária da Região de Chapecó (Unochapecó); E-mail: giselevieira@ unochapeco.edu.br

4 Doutor em Biodiversidade Animal; Docente do Programa de Pós-Graduação em Ciências da Saúde (PPGCS). Escola de Saúde. Universidade Comunitária da Região de Chapecó (Unochapecó); E-mail: junir@unochapeco.edu.br
} 
potencialidade de produção de alimentos, ainda é preciso avançar, quantitativamente, na participação deste modelo de aquisição de alimentos para a alimentação escolar.

Palavras-chave: Agricultura Familiar, Política Pública, Segurança Alimentar.

\begin{abstract}
This work was intended to contextualize family farming and its link with the National School Feeding Program in the state of Santa Catarina in the period from 2012 to 2017. To that end, an analytical document-based study was developed, held in a longitudinal and retrospective perspective. As a data source, we used the public calls for the purchase of foods from family farming for school meals and, complementarily, based on the School Census, the reports on the number of students enrolled in the public school network of the municipalities that published notices, as well as socioeconomic and demographic indicators of the municipalities of Santa Catarina and the Brazilian Agricultural Census. A total of 821 public notices were analyzed, published by 231 municipalities in Santa Catarina, which are predominantly classified as smallsized. When size was associated with quality indicators of purchase, such as the per capita of healthy food represented by fruits, vegetables and legumes, we found that small-sized municipalities purchased $46.57 \%$ more healthy foods than large ones in the last triennium. As for the percentage of food purchases from family farming, we noted that, as of 2014, there was a significant increase in the average purchase. Knowing the characteristics of the state and its potential for food production, it is still necessary to advance, quantitatively, in the participation of this food procurement model for school feeding.
\end{abstract}

Keywords: Family Farming, Public Policy, Food Security

\title{
Resumen
}

El objetivo de este trabajo fue contextualizar la agricultura familiar y su enlace con el Programa Nacional de Alimentación Escolar en el estado de Santa Catarina durante el período comprendido entre 2012 y 2017. Para ello, se desarrolló un estudio analítico de base documental, desarrollado en una perspectiva longitudinal retrospectiva. Como fuente de datos, se utilizaron los avisos de convocatoria pública para la adquisición de alimentos de la agricultura familiar para la alimentación escolar y, complementariamente, a partir del Censo Escolar, los informes sobre el número de alumnos matriculados en la red pública de enseñanza de los municipios que publicaron avisos, así como los indicadores socioeconómicos y demográficos de los municipios de Santa Catarina y del Censo Agropecuario Brasileño. Se analizaron 821 avisos de convocatorias públicas, publicados por 231 municipios de Santa Catarina, que se clasifican predominantemente como de pequeño tamaño. Cuando se asoció el tamaño con los indicadores de calidad de la adquisición, como la cantidad per cápita de alimentos saludables representada por frutas, verduras y legumbres, se comprobó que los municipios pequeños adquirieron un 46,57\% más de alimentos saludables que los grandes municipios en el último trienio. En cuanto al porcentaje de adquisición de alimentos por parte de la agricultura familiar, se notó que, a partir de 2014, hubo un aumento significativo en la adquisición. Conociendo las características del estado y su potencial para la producción de alimentos, aún es necesario avanzar, cuantitativamente, en la participación de este modelo de adquisición de alimentos para la alimentación escolar.

Palabras clave: Agricultura Familiar, Política Pública, Seguridad Alimentaria 


\section{INTRODUÇÃO}

O estado de Santa Catarina, com área territorial de $95.730,684 \mathrm{~km}^{2}$, tem população estimada em 2020 de 7.252.502 pessoas e Índice de Desenvolvimento Humano (IDH) alto (0,774). Especificamente, os municípios catarinenses possuem Índice de Desenvolvimento Humano Municipal (IDHM) entre muito alto e médio, não havendo cidades com IDHM baixo e muito baixo no estado. A população é predominantemente urbana $(83,99 \%)$, e o rendimento nominal mensal domiciliar per capita em 2020 foi de R\$1632,00. O estado é constituído por 295 municípios, divididos em seis mesorregiões (Oeste catarinense, Norte Catarinense, Sul Catarinense, Serrana, Vale do Itajaí e Grande Florianópolis) (IBGE, [201-]; BRASIL, 2013a).

Sobre as condições agrícolas do estado, Santa Catarina se destaca pela maior proporção de área ocupada pela agricultura familiar dentre os estados da região Sul do país. Em Santa Catarina, $78 \%$ das propriedades rurais são da modelo agricultura familiar, ocupando 364 mil pessoas e 2,45 milhões de hectares cultivados. Em 2017, a agricultura familiar foi responsável por 23\% do valor total da produção dos estabelecimentos agropecuários do Brasil, em Santa Catarina por 50,68\%, no Rio Grande do Sul por 37,36\% e no Paraná por 27,39\%. Nacionalmente, Santa Catarina ocupa o quinto lugar em termos do percentual do valor total de produção proveniente da agricultura familiar, sendo precedida pelo Amazonas, Amapá, Acre e Sergipe. Destaca-se que $77 \%$ dos estabelecimentos agropecuários são classificados como agricultura familiar no Brasil, representando aproximadamente 3,9 milhões de estabelecimentos, com área de cultivo de 80,9 milhões de hectares, correspondentes a $23 \%$ da área de todos os estabelecimentos agropecuários do País (IBGE, 2017).

De acordo com a Lei n. 11.326, de 24 de julho de 2006, considera-se agricultor familiar aquele que pratica atividades no meio rural e que não detém área maior do que quatro módulos fiscais, utilizando predominantemente mão-de obra da própria família, com a qual dirige seu estabelecimento ou empreendimento, de cujas atividades econômicas origina-se percentual mínimo da renda familiar (BRASIL, 2006a; BRASIL, 2017a).

Para a Organização das Nações Unidas para a Alimentação e a Agricultura (FAO), agricultura familiar é um meio de organização das produções agrícola, florestal, pesqueira, pastoril e aquícola, gerenciadas e operadas por uma família e predominantemente dependente de força de trabalho familiar, tanto de mulheres quanto de homens, estando as famílias e os seus 
estabelecimentos produtivos ligados por funções econômicas, ambientais, sociais e culturais (FAO, 2013).

No contexto do desenvolvimento e fortalecimento da agricultura familiar no Brasil, existe uma longa trajetória permeada por desafios e dificuldades que ainda perduram neste segmento. Historicamente, destacam-se inciativas governamentais de fortalecimento da agricultura familiar, tendo sido criado, em 1996, o Programa Nacional de Fortalecimento da Agricultura Familiar (PRONAF), voltado para o crédito agrícola e o apoio institucional aos agricultores familiares. Com base nos debates promovidos neste âmbito, a importância da agricultura familiar no sistema alimentar ficou mais evidente para a sociedade, o que resultou, nos anos 2000, em maior representatividade desse segmento nas ações de Segurança Alimentar e Nutricional (SAN) (BRASIL, 2018).

Em 2003, foi recriado o Conselho Nacional de Segurança Alimentar e Nutricional (CONSEA), criado o Ministério Extraordinário de Segurança Alimentar e Combate à Fome (MESA), lançada a Estratégia Fome Zero, instituído o Programa Bolsa Família (PBF) e criado o Programa de Aquisição de Alimentos (PAA), o qual possibilitou aos agricultores familiares participarem do mercado institucional, comercializando seus produtos para estados e municípios. Em 2006, foi instituída a Lei n. 11.326, que estabelece as diretrizes para a formulação da Política Nacional da Agricultura Familiar e Empreendimentos Familiares Rurais. Já em 2009, foi aprovada a Lei n. 11.947, que indica o apoio ao desenvolvimento sustentável como uma das diretrizes da alimentação escolar, com incentivos para a aquisição de gêneros alimentícios diversificados, produzidos em âmbito local e, preferencialmente, pela agricultura familiar e pelos empreendedores familiares rurais (BRASIL, 2009a).

Essa Lei representa um marco, na medida em que estabelece que, no mínimo, 30\% do total dos recursos financeiros repassados pelo Fundo Nacional de Desenvolvimento da Educação (FNDE), no âmbito do PNAE, deverão ser utilizados na aquisição de gêneros alimentícios diretamente da agricultura familiar, dispensando o processo licitatório e fazendo uso de editais de chamada pública (BRASIL, 2018). Esta legislação vem se consolidando ao longo dos anos e tornando mais evidente a intencionalidade de constituir o PNAE como um instrumento de promoção da saúde e de desenvolvimento local sustentável (SZINWELSKI; TEO, 2016).

É importante destacar, ainda, que as compras públicas realizadas por meio do PAA e do PNAE promovem articulação entre a produção da agricultura familiar e as demandas alimentares dos escolares e da população em situação de vulnerabilidade, valorizando práticas produtivas e 
hábitos alimentares locais (GRISA; TECCHIO; CHECHI; SABOURIN, 2020). Além disso, o fortalecimento do PNAE e o apoio à agricultura familiar vêm contribuindo com avanços no acesso à alimentação no país e, portanto, com a SAN, agindo no enfrentamento da pobreza e da fome e, simultaneamente, colaborando para qualificar as condições de vida e saúde da população em geral (BRASIL, 2018; TEO et al., 2020).

Neste sentido, o objetivo deste trabalho foi contextualizar a agricultura familiar e a sua vinculação ao Programa Nacional de Alimentação Escolar (PNAE) no estado de Santa Catarina no período de 2012 a 2017. Para tanto, este trabalho está constituído, além desta introdução, por quatro seções, a saber: referencial teórico, método, resultados e discussão e considerações finais.

\section{TRAJETÓRIA HISTÓRICA DO PNAE E A APROXIMAÇÃO COM A AGRICULTURA FAMILIAR}

O PNAE é conhecido mundialmente como uma estratégia fundamental na garantia do Direito Humano à Alimentação Adequada (DHAA) e da SAN. Neste contexto, destaca-se que alguns acordos internacionais foram firmados com a Organização das Nações Unidas para Alimentação e Agricultura (FAO) e com o Programa Mundial de Alimentos (PMA), por meio da Agência Brasileira de Cooperação do Ministério das Relações Exteriores, com o objetivo de apoiar o desenvolvimento de Programas de Alimentação Escolar Sustentáveis em Países da América Latina, Caribe, África e Ásia, sob os princípios da SAN e do DHAA (FNDE, [201-a]).

Ampliando a discussão sobre o histórico do PNAE, vale ressaltar que o Decreto n. 37.106 de 1955, que instituiu a Campanha de Merenda Escolar, vinculada ao Ministério da Educação, tinha como responsabilidade incentivar empreendimentos públicos e privados que favorecessem à alimentação escolar, por meio de assistência técnica e financeira, adotar medidas que melhorassem a qualidade nutricional e promovessem o barateamento do produtos utilizados no preparo das refeições, assim como a aquisição de produtos nas fontes produtoras ou por convênio internacional, facilitando a logística de pagamento, transporte e preços. O mesmo Decreto indicava, ainda, que a Campanha deveria ser realizada por meio da criação de cantinas escolares por iniciativa de entidades públicas ou privadas, sendo seu financiamento efetivado com recursos específicos. Ao longo dos anos, a Campanha sofreu modificações em sua nomenclatura, sendo denominada, em 1956, de Campanha Nacional de Merenda Escolar e, em 1965, de Campanha Nacional de Alimentação Escolar (FNDE, [201-a]). 
A partir de 1979, a Campanha Nacional de Alimentação Escolar, que fazia parte do II Programa Nacional de Alimentação e Nutrição (PRONAN), passou a ser chamada de Programa Nacional de Alimentação Escolar (PNAE) (FNDE, [201-a]). Em 1994, a Lei n. 8.913/94 determinou a descentralização dos recursos para execução do PNAE.

Atualmente, o programa é mantido pelo FNDE, vinculado ao Ministério da Educação, que presta assistência técnica e financeira e executa ações de implementação de políticas públicas. As entidades executoras são estados, municípios, Distrito Federal e escolas federais. Ainda, compondo o programa, existe a unidade executora, que representa a comunidade escolar e é responsável pelo recebimento de recursos financeiros que podem ser transferidos pelas entidades executoras, em favor das escolas que representa, e, por fim, o Conselho de Alimentação Escolar (CAE) (FNDE, [201-a]).

No contexto de estruturação do PNAE, o Conselho de Alimentação Escolar (CAE) foi instituído em cada município brasileiro com a reedição da Medida Provisória n. 1.784/98, no ano 2000, sob o n. 1979-19 (BRASIL, 2000). A constituição deste Conselho é requisito obrigatório para que os recursos para compra de alimentos sejam repassados pelo FNDE para os municípios. Destaca-se, ainda, que este Conselho não deve ser uma mera formalidade, mas atuante, considerando que é a partir dele que a sociedade pode acompanhar a implementação do programa e a utilização dos recursos financeiros recebidos. Além disso, o controle social exercido pelos CAEs estaduais, municipais ou distrital deve estar comprometido com a SAN da população escolar (BRASIL, 2015).

No âmbito do PNAE e da agricultura familiar, o CAE representa um mediador no diálogo entre prefeituras, agricultores e ou cooperativas. Entretanto, a frágil atuação destes conselhos ainda é um desafio a ser enfrentado por diversos municípios, mas que precisa melhorar considerando que conselhos são espaços privilegiados para o diálogo interdisciplinar e intersetorial, o que pode contribuir com o enfrentamento dos obstáculos que se apresentam (TEO; MOSSMANN; TAGLIETTI, 2017).

Outro aspecto a ser considerado na organização do PNAE é a obrigatoriedade do Nutricionista na execução do programa, o que vem fazendo crescer o quantitativo de profissionais atuando nesta política pública no curso dos anos. Já em 1994, a Lei n. 8.913 indicava que a elaboração de cardápios do PNAE era responsabilidade dos estados e municípios, por meio de Nutricionista capacitado para esta atividade, respeitando os hábitos alimentares de cada localidade e sua vocação agrícola, o que se tornou obrigatório por meio da Resolução/CD/FNDE n. 32, de 10 
de agosto de 2006. Em 2009, com a Lei n. 11.947, ficou estabelecido que a reponsabilidade técnica pela alimentação escolar é do Nutricionista, e a Resolução CD/FNDE n. 26 de 2013 complementa que este profissional deve estar obrigatoriamente vinculado ao setor de alimentação escolar da entidade executora, o que é fortalecido pela Resolução n.06 de 2020 (BRASIL, 2017b; BRASIL, 2020).

Em um percurso histórico de conquistas e melhorias no PNAE, em 2009, a partir da Lei n. 11.947, ficou estabelecido que 30\% dos repasses do FNDE fossem investidos na aquisição de alimentos da agricultura familiar, sendo que as resoluções n. 38/2009 e n. 26/2013 previam que este modelo de aquisição poderia dispensar o processo licitatório, o que é mantido pela Resolução n. 06 de 2020, em vigência (BRASIL, 2009a; BRASIL, 2009b; BRASIL, 2013b; BRASIL, 2020).

É importante salientar que o mínimo estabelecido pela legislação para aquisição de alimentos da agricultura familiar é de 30\%, mas os esforços são para ampliação para 100\% dos recursos, pois a agricultura familiar local tem condições de oferecer produtos frescos, saudáveis e que respeitam a cultura e a produção agrícola local (BRASIL, 2016a).

Estudo de Baccarin et al. (2017), que sistematizou variáveis que contribuem para avaliação das compras da agricultura familiar para alimentação escolar, a partir de chamadas públicas de dois estados do Sul do país e um do Sudeste, verificou que o cumprimento da legislação vem aumentando, apesar de o número de agricultores fornecedores da maioria dos municípios ser pequeno. Outra fragilidade observada é que, em vários casos, as chamadas públicas apresentam insuficiência de informações, o que prejudica a organização do agricultor familiar e a eficiência do processo.

Em 2010, os 30\% a serem aplicados no PNAE corresponderam a aproximadamente um bilhão de reais e, atualmente, a agricultura familiar é responsável por $70 \%$ dos alimentos consumidos no Brasil (BRASIL, 2014).

Já se avançou muito no Brasil na construção de políticas relacionadas à SAN, na organização do PNAE e nas compras públicas, mas ainda é preciso fortalecer, especialmente as compras da agricultura familiar pelo PNAE, pois ainda existem muitas dificuldades neste processo, como as relativas à melhoria de infraestrutura, capacitação de colaboradores das escolas, assistência técnica e melhoria na capacidade dos agricultores, resolução de entraves na logística de entrega e capacitação de Nutricionistas, para que desenvolvam cardápios nutricionalmente adequados e que representem a produção e a cultura alimentar locais. Apesar destes desafios, é louvável dizer que o Brasil foi pioneiro nesta iniciativa e vem sendo modelo para outros Países. 
Além disso, não há dúvidas dos efeitos positivos desta iniciativa para agricultores, comunidade, alunos e escolas (SCHWARTZMAN et al., 2017)

Reafirmando os benefícios e desafios deste modelo de aquisição, pesquisa realizada em Ribeirão Grande (SP) aponta que o programa de compra da agricultura familiar dos municípios melhorou questões econômicas e de valorização da agricultura. Entretanto, a produção de alimentos tem se caracterizado pela especialização por alguns cultivos, crescimento do uso de insumos sintéticos para a produção, aumento do consumo de itens industrializados na alimentação das famílias e redução da produção para autoconsumo. Nesta lógica, é preciso que as políticas públicas também fortaleçam a ideia de associação entre a produção e o autoconsumo, com o objetivo de manter a autonomia dos produtores e a SAN. Além disso, o incentivo à produção de agroecológicos precisa ser ampliado, pensando na proteção humana e do meio ambiente (CAMARGO; NAVAS, 2017), em uma perspectiva de saúde única.

Ressalta-se, ainda, que o Brasil tem sido modelo em termos de alimentação escolar para outros países, no que se refere a sua organização e, especialmente, ao modelo de aquisição de alimentos da agricultura familiar, o qual vem sendo chamado pela literatura internacional de Home-Grown School Feeding (HGSF) e que combina o incentivo à produção agrícola local com melhorias nos programas de alimentação escolar (ESPEJO; BURBANO; GALLIANO, 2009; BUNDY et al., 2009). Em suma, o HGSF trabalha com uma sinergia de objetivos, no sentido de melhorar a renda dos agricultores, o desenvolvimento local e a atenção à saúde pública (TRICHES, 2015).

Esta inciativa de oferta de alimentos mais saudáveis no ambiente escolar, por meio da agricultura familiar, vem ao encontro das diretrizes, instituídas por meio da Portaria Interministerial n. 1010/2006, para a promoção da alimentação saudável nas escolas de educação infantil, fundamental e nível médio das redes pública e privada, em âmbito nacional, favorecendo o desenvolvimento de ações que promovam e garantam a adoção de práticas alimentares mais saudáveis no ambiente escolar (BRASIL, 2006b).

A compra de alimentos provenientes da agricultura familiar, para atender às demandas do PNAE, é uma maneira de reconhecer a necessidade de buscar uma produção de alimentos que atenda às necessidades nutricionais da população e garanta o fortalecimento da agricultura familiar. Neste sentido, o programa é uma estratégia de, simultaneamente, oferecer alimentos mais saudáveis a alunos e estimular a agricultura familiar no País. Desta forma, o PNAE, dentre suas inúmeras potencialidades, age também na insegurança alimentar no campo, (re)organiza 
comunidades, dinamiza a economia local, amplia a oferta de alimentos de qualidade e valoriza a produção familiar (BRASIL, 2014).

No histórico documental do PNAE, desde sua origem, a indicação da importância de incentivar a compra de alimentos in natura e de produção local esteve presente, com o objetivo principal de redução de custos. Com a descentralização dos recursos para a aquisição de alimentos no PNAE, foi possível incluir alimentos in natura no cardápio, pois permitiu a compra de alimentos locais que, consequentemente, chegam mais frescos às escolas, o que não era possível com a gestão centralizada, caracterizada pela oferta de alimentos industrializados. Na década de 1990, com a criação do PRONAF, as conferências de SAN, a retomada do CONSEA e a criação do plano safra, é que a justificativa de incentivo e fortalecimento da agricultura familiar começa a aparecer em documentos oficiais relacionados ao PNAE. Com o passar dos anos, a importância da alimentação saudável começou a ser incorporada aos documentos do PNAE, em consonância com o fortalecimento da SAN, a partir de 2008 (CARVALHOSA; BURLANDY, 2017).

\section{METODOLOGIA}

Este é um estudo do tipo analítico de base documental, desenvolvido em uma perspectiva longitudinal retrospectiva.

As fontes de dados desta pesquisa foram os editais de chamada pública para compra de alimentos da agricultura familiar para a alimentação escolar, divulgados pelos municípios de Santa Catarina, em seus sites oficiais, no período de 2012 a 2017.

Inicialmente, foram coletados todos os editais disponibilizados em acesso público pelos 295 municípios catarinenses no período de 2012 a 2017. Os editais foram, primeiramente, buscados nos sites das prefeituras municipais, que são monitorados periodicamente pela equipe da pesquisa matricial Observatório da aquisição de alimentos da agricultura familiar para a alimentação escolar em Santa Catarina, à qual este projeto está vinculado. Elucida-se que, neste monitoramento, que nos casos em que não foram encontrados editais nos sites pesquisados, realizou-se busca livre no Google e, adicionalmente, valendo-se das prerrogativas dadas pela Lei da Transparência (BRASIL, 2011), enviou-se solicitação por e-mail aos municípios, como recurso para a localização do maior número possível de chamadas públicas.

A determinação do período deu-se pelo fato do monitoramento ter iniciado pelo projeto matricial em 2012 e no primeiro semestre de 2018 foi finalizada a constituição do banco de dados 
e iniciado o tratamento das informações coletadas, não havendo viabilidade de inclusão de novos anos após 2017, tendo em vista o percurso metodológico e a amplitude desta pesquisa.

Além destes documentos, foram coletados, a partir do Censo Escolar de cada ano, os relatórios relativos ao número de alunos matriculados na rede de ensino pública dos municípios que publicaram editais para a aquisição de alimentos da agricultura familiar para a alimentação escolar, nos respectivos anos avaliados nesta pesquisa. Estes relatórios também são de acesso público e estão disponíveis no site do Instituto Nacional de Estudos e Pesquisas Educacionais Anísio Teixeira (INEP, 2012; 2013; 2014; 2015; 2016; 2017).

Finalmente, com o objetivo de caracterizar as regiões deste estudo, foi coletado o conjunto de registros públicos divulgado sobre os indicadores socioeconômicos e demográficos dos municípios de Santa Catarina por meio do Instituto Brasileiro de Geografia e Estatística (IBGE) (IBGE, [201-]). Com relação à agricultura familiar, no Brasil e em Santa Catarina, foram utilizadas as informações do Censo Agropecuário Brasileiro de 2017 (IBGE, 2017).

As variáveis com as quais o estudo opera são a) os percentuais de recursos financeiros aplicados na aquisição de alimentos da agricultura familiar disponibilizados no site do FNDE de acordo com as prestações de contas realizadas pelas Entidades Executoras, b) o porte dos municípios, que foram classificados, segundo o IBGE (2010), c) o ano do período de estudo (2012, 2013, 2014, 2015, 2016 e 2017), d) o per capita de alimentos saudáveis (frutas, hortaliças e leguminosas) resultante das soma das quantidades das chamadas públicas dividida pelo alunado de cada município, e) número de chamas públicas e f) alunado do estado de Santa Catarina.

Foi realizada análise descritiva dos dados (média e desvio padrão). Para comparar e avaliar o per capita de alimentos saudáveis entre as mesorregiões e o porte dos municípios, foi utilizada uma análise de ordenação Non-metric Multidimensional Scaling (NMDS). Foi utilizado BrayCurtis como índice de associação e a análise foi realizada com o programa estatístico Primer 6.1.9. (CLARKE; GORLEY, 2005). Essa análise agrupa as amostras por similaridade quanto à composição.

Para verificar a existência de correlação entre as variáveis do estudo (percentual de aplicação de recursos financeiros na aquisição de alimentos da agricultura familiar, porte dos municípios e per capita de alimentos saudáveis), foi utilizado o teste de correlação de Pearson. As amostras foram submetidas previamente ao teste de Normalidade (Shapiro-Wilk) e, posteriormente, aplicado o índice de correlação de Pearson. Ainda, foi construído um diagrama de 
dispersão para apresentar a relação entre as duas variáveis. A análise foi realizada com o auxílio do software Past (HAMMER; HARPER; RYAN, 2001).

\section{APROXIMAÇÃO ENTRE A AGRICULTURA FAMILIAR E O PNAE}

Foram coletados 865 editais de chamada pública divulgados pelos municípios de Santa Catarina no período de 2012 a 2017. Deste total, foram excluídos 44 editais por não apresentarem a lista de alimentos ou as respectivas quantidades de cada produto, por apresentarem quantidade per capita não compatível com o público atendido, por terem sido chamadas revogadas, desertas ou fracassadas, restando 821 documentos válidos para a análise proposta nesta pesquisa, o que representa 94,91\% dos editais coletados. Estas chamadas foram publicadas por 231 municípios, o que representa 78,30\% do total do estado de Santa Catarina (Figura 1). 
Figura1- Distribuição dos editais de chamada pública para aquisição de alimentos da agricultura familiar para a alimentação escolar analisados, por ano, dos municípios catarinenses, Brasil, 20122017.

Mun.: Municípios

CP: Chamadas Públicas

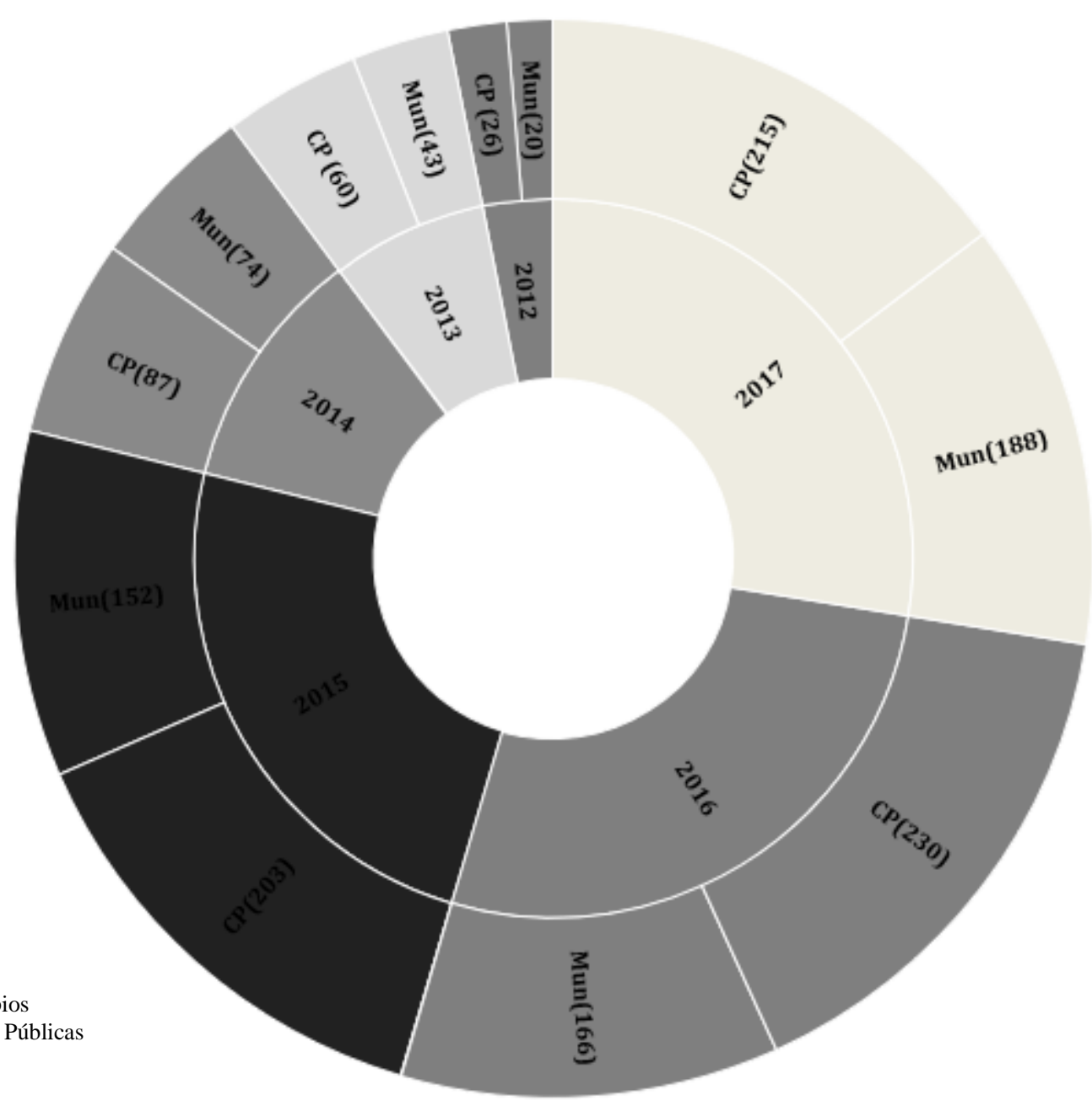

Fonte: Elaboração dos autores (2020) a partir das publicações localizadas e disponibilizadas por cada município do Estado (2017)

Observa-se que, entre o primeiro e o segundo triênios, ocorreu um aumento expressivo (274,56\%) no número de editais divulgados pelos municípios catarinenses, de 173 no triênio 2012 2014 para 648 no triênio 2015-2017 (Figura 1). Essa constatação indica que o processo de consolidação deste modelo de aquisição de alimentos para a alimentação escolar trilhou seis anos (2009-2014), desde a promulgação da Lei n. 11.947, para ampliar de forma significativa a sua abrangência a partir de 2015. Isso sugere que uma política pública desta magnitude precisa de, aproximadamente, uma década para atingir, de forma mais homogênea, o território de abrangência pretendido - no caso em análise, o estado de Santa Catarina. No entanto, apesar desse avanço, é 
importante registrar que ainda existem diferenças em termos do apoio recebido para o desenvolvimento da agricultura familiar nos municípios, dos esforços intersetoriais para viabilizar o mercado para a agricultura familiar em meio às compras institucionais, da diversidade econômica, social, cultural e ambiental que um estado pode conter.

Sobre a distribuição das chamadas públicas por mesorregião do estado de Santa Catarina, observou-se variação no número de municípios e no quantitativo de chamadas públicas em cada região (Figura 2).

Figura 2- Distribuição, de acordo com sua representatividade numérica, dos editais de chamada pública incluídos na pesquisa por mesorregião do estado de Santa Catarina, Brasil, 2012-2017.

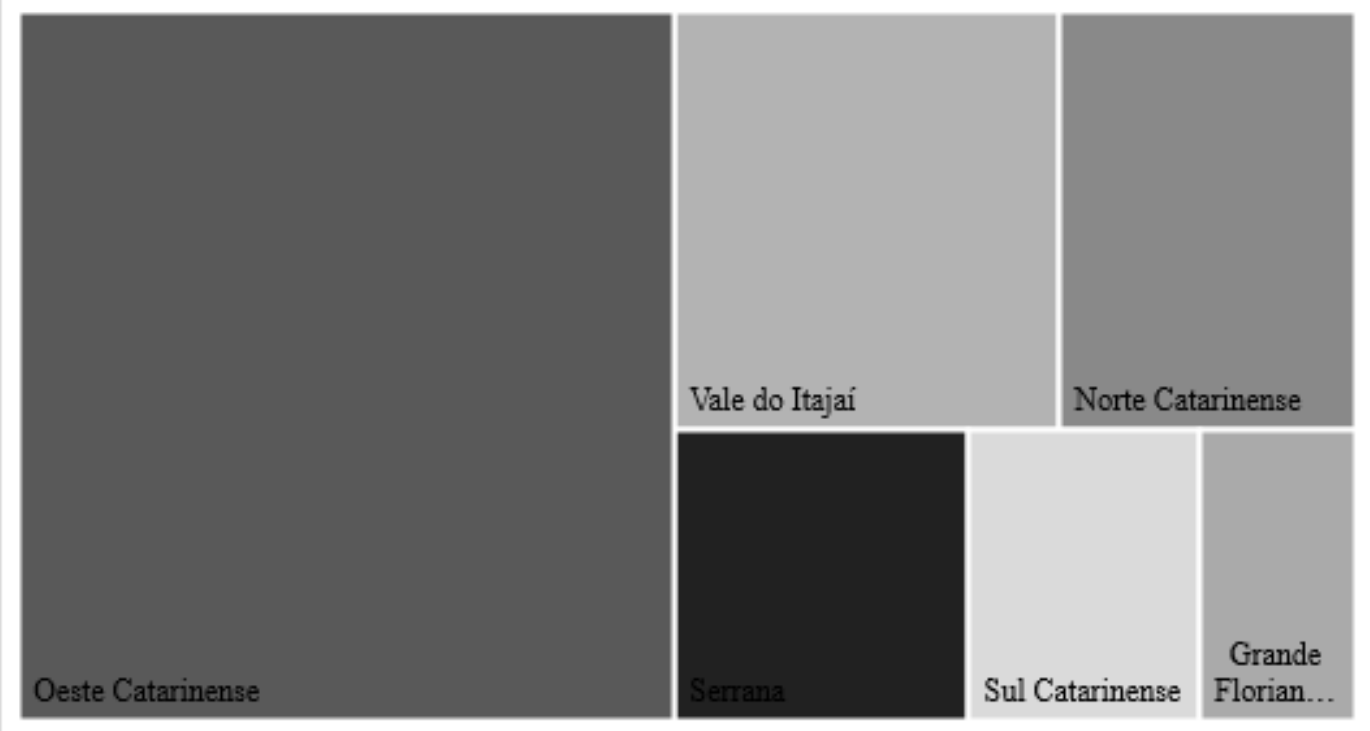

Fonte: Elaboração dos autores (2020) a partir das publicações localizadas e disponibilizadas por cada município do Estado (2017)

Diante do cenário apresentado (Figura 2), e considerando a diversidade econômica, social, cultural e ambiental de Santa Catarina, pondera-se que uma política pública com estas características precisa ir muito além da normatização de processos, devendo contemplar as singularidades e condições de produção e comercialização das diferentes regiões do estado.

Teo et al. (2020) apontaram como dificuldades na articulação entre a agricultura familiar e a alimentação escolar a assistência técnica insuficiente, dificuldades de logística, insuficiência da produção local e resistência dos agricultores familiares às exigências sanitárias e à realização dos investimentos necessários. Com base neste diagnóstico, é possível considerar que a evolução no número de chamadas públicas, ao longo dos anos, também pode estar relacionada com a superação destes obstáculos. Essa superação exige movimentos intersetoriais, evolução temporal, 
investimento financeiro, formação para qualificar a produção e a comercialização de alimentos produzidos pela agricultura familiar e, ainda, conscientização e engajamento dos diferentes atores sociais envolvidos nesse processo.

Para Assis, França e Coelho (2019), com base em estudo que objetivou analisar os principais desafios para a venda da agricultura familiar ao PNAE, a execução da política pública exige o envolvimento das organizações de agricultores, instituições de assistência técnica e extensão rural e setores e órgãos ligados à aquisição de alimentos da agricultura familiar em cada município. Esse envolvimento, para ser efetivo, precisa se constituir como um movimento de aprendizagem para ambas as partes no que se refere às mudanças necessárias no processo produtivo, no planejamento da produção, na organização de documentos e produtos para as chamadas públicas. Também, no reconhecimento das especificidades da agricultura familiar local, na elaboração de cardápios que sejam coerentes com a produção local, na regularização de produtos, na instituição da nova modalidade de compra pública e na interação entre setores que, normalmente, não interagiam.

Neste sentido, vale destacar que, em Santa Catarina, em termos de produção agrícola, a maior atividade de produção alimentar está concentrada na mesorregião Oeste do estado (SANTA CATARINA, [201-]). Já quanto às demais mesorregiões, a da Grande Florianópolis destaca-se nos setores de tecnologia, turismo, serviços e construção civil; o Norte Catarinense é polo tecnológico, moveleiro e metal-mecânico; a mesorregião Serrana tem forte indústria de papel, celulose e madeira; o Sul Catarinense destaca-se pelos segmentos de vestuário, carbonífero, cerâmico e de plásticos descartáveis; no Vale do Itajaí, predominam as indústrias têxtil e do vestuário, naval e de tecnologia (SANTA CATARINA, [201-]). As características das diferentes mesorregiões do estado podem ser responsáveis pela quantidade de municípios - em cada uma delas - em que se observa adesão da agricultura familiar local à comercialização de alimentos para o PNAE. Como exemplo dessa ponderação, aponta-se a mesorregião Oeste Catarinense, em que 87,29\% dos municípios têm chamadas públicas registradas neste estudo (Figura 2).

Outro aspecto importante a ser considerado, e que pode estabelecer relação com a disponibilidade de produtos locais, pela dinâmica econômica assumida, é a composição das mesorregiões do estado em municípios de pequeno, médio e grande porte (Figura 3). 
Figura 3-Número de municípios em cada mesorregião do estado de Santa Catarina, por porte*, Santa Catarina, 2020.

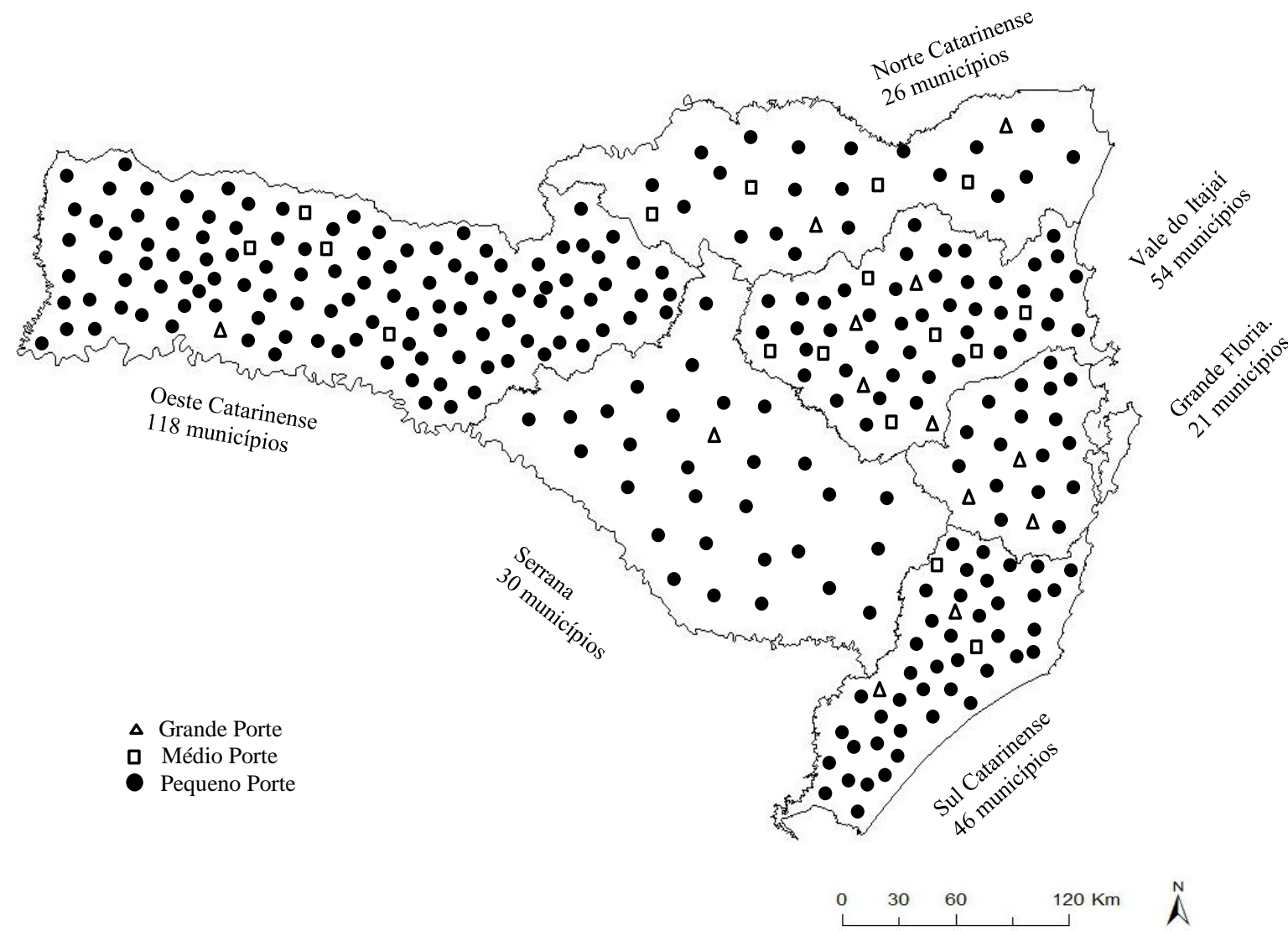

Fonte: Elaboração dos autores (2020) a partir de IBGE (2010; estimativa 2019).

*Pequeno porte: população $\leq 50$ mil habitantes; médio porte: $50.001 \leq$ população $\leq 100$ mil habitantes; grande porte: população > 100 mil habitantes.

Constata-se que o estado de Santa Catarina é formado, predominantemente, por municípios de pequeno porte $(n=265 ; 89,83 \%)$, sendo que, deste total, $40 \%(n=106)$ são municípios com população igual ou inferior a 5.000 habitantes, 22,64 \% (n=60) têm população > 5000 e $\leq 10$ mil habitantes, 22,26\% $(n=59)$ têm população $>10.000$ e $\leq 20.000$ habitantes, e $15,09 \%(n=40)$ têm população $>20$ mil e $\leq 50$ mil habitantes.

Nesta pesquisa, quando o porte foi associado com indicadores de qualidade da aquisição, como o per capita de alimentos saudáveis representado por frutas, hortaliças e leguminosas, houve significância estatística com p<0,02 para o último triênio (2015-2017). Constatou-se, a partir das médias anuais, que os municípios de pequeno porte compraram 46,57\% mais alimentos saudáveis do que os de grande porte no segundo triênio, sendo observadas médias per capita de alimentos saudáveis de 56,71g, 43,76g e 30,30g para os municípios de pequeno, médio e grande porte, respectivamente. Quando analisados os seis anos de aquisição, de maneira conjunta, as médias 
anuais indicam que os municípios de pequeno porte compraram 32,50\% mais alimentos saudáveis do que os de grande porte, e 32,62\% mais do que os de médio porte. As médias per capita de alimentos saudáveis de municípios de pequeno, médio e grande porte foram, respectivamente, de $57,97 \mathrm{~g}, 39,06 \mathrm{~g}$ e $39,13 \mathrm{~g}$ no período de 2012-2017.

O per capita de alimentos saudáveis e o porte dos municípios evidenciou similaridade de $70 \%$ entre as seis mesorregiões nos seis anos. Observa-se que a maior similaridade ocorreu entre grupos que contêm mais municípios de pequeno e médio porte, sendo que os de grande porte não se agrupam aos demais, demonstrando diferença nos per capitas (Figura 4).

Figura 4-Similaridade do per capita de alimentos saudáveis por mesorregião do estado de Santa Catarina, Brasil, 2012-2017.

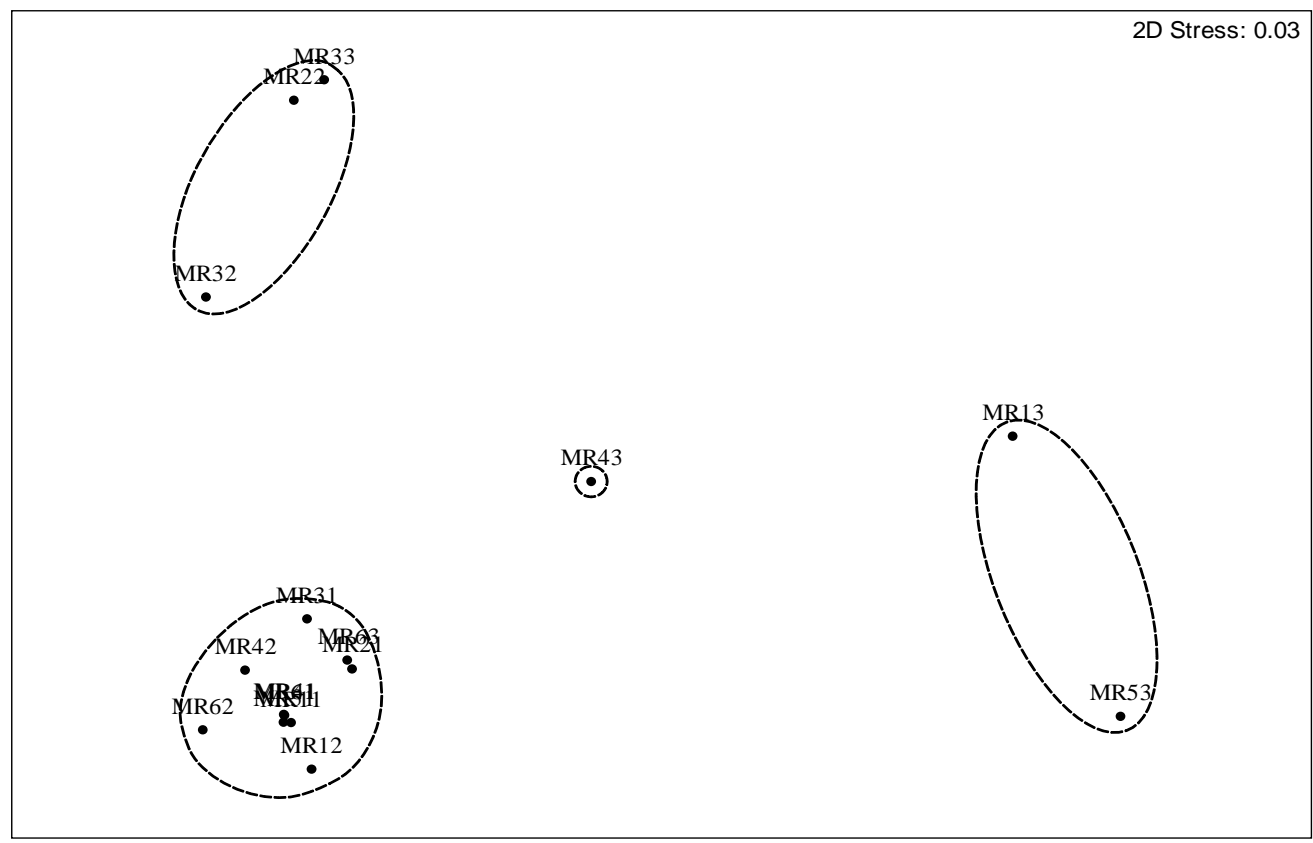

Fonte: Elaboração dos autores (2020)

$\mathrm{Na}$ análise de relação entre percentual de compra da agricultura familiar e porte do município, foi constatado um $\mathrm{p}<0,04$. Na Figura 5 é apresentado o comportamento do percentual de compra por porte em cada ano do período de estudo. 
Figura 5 - Percentual de compra da agricultura familiar em relação ao porte do município, por ano, de municípios catarinenses, Brasil, 2012-2017.

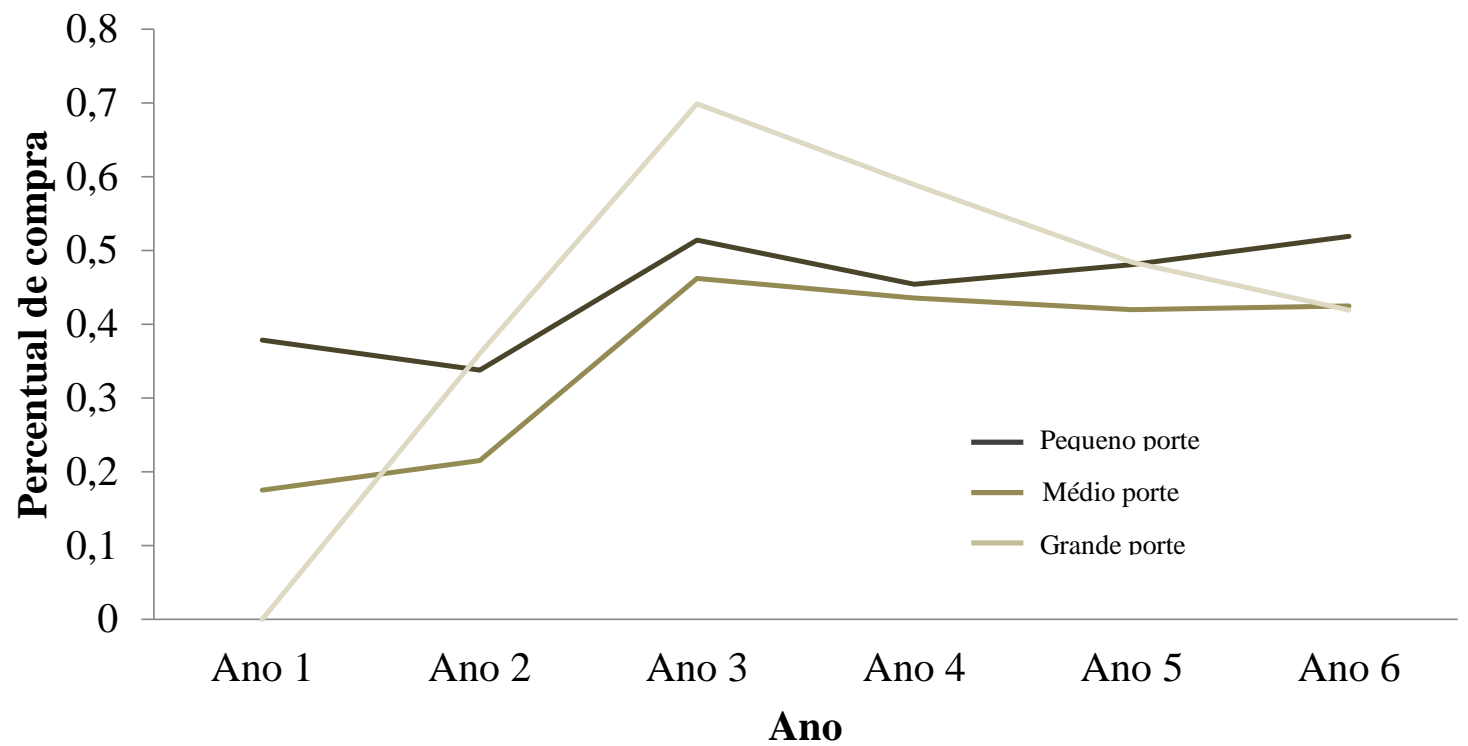

Fonte: Elaboração dos autores (2020).

Registra-se que existe uma tendência de aumento do percentual de compra no ano de 2016 para municípios de pequeno e médio porte, e de redução para os de grande porte. Municípios de pequeno e médio porte apresentaram semelhanças no percentual de compra durante os anos do estudo. Apesar de os de médio porte iniciarem o período com um percentual muito abaixo dos de pequeno porte, houve um crescimento que, a partir de 2014, os situa em um nível mais próximo dos municípios de pequeno porte.

Estudo que caracterizou os municípios brasileiros quanto à compra de alimentos da agricultura familiar para o PNAE apontou menores percentuais de utilização de recursos nas compras de alimentos da agricultura familiar por municípios de grande porte. Já os municípios de pequeno e médio porte apresentaram comportamento semelhante. Esta tendência foi observada entre as regiões e estados brasileiros, exceto para a região Centro-Oeste, que apresentou maior percentual de compras para municípios de grande porte na comparação com os de pequeno porte. As regiões Sudeste e Sul apresentaram frequências mais homogêneas da realização da compra, independentemente do porte dos municípios (MACHADO et al., 2018).

Ainda sobre o percentual de aquisição de alimentos da agricultura familiar, observa-se que, em 2014, ocorreu um aumento significativo na média do percentual de utilização dos recursos financeiros na aquisição de alimentos da agricultura familiar, que parece se estabilizar nos anos que se seguem, podendo indicar que, no estado de Santa Catarina, após cinco anos de DOI: http://dx.doi.org/10.22295/grifos.v31i56.6572 | Edição Vol. 31, Núm. 56, 2022. 
implementação da Lei, há uma tendência de estabilização na média percentual de aquisição, mas que pode se prolongar no tempo necessário de estabilização considerando as singularidades de cada município. No primeiro triênio, a média foi de 43,17\% e no segundo, de 48,50\%, representando $12,35 \%$ de aumento na transição do primeiro para o segundo triênio (Figura 6). Na análise do percentual de aquisição da agricultura familiar por ano, constatou-se diferença significativa entre os anos $(\mathrm{p}<0,01)$.

Figura 6- Média anual e por triênio do \% de recursos aplicados na aquisição de alimentos da agricultura familiar para a alimentação escolar de municípios catarinenses, Brasil, 2012-2017.

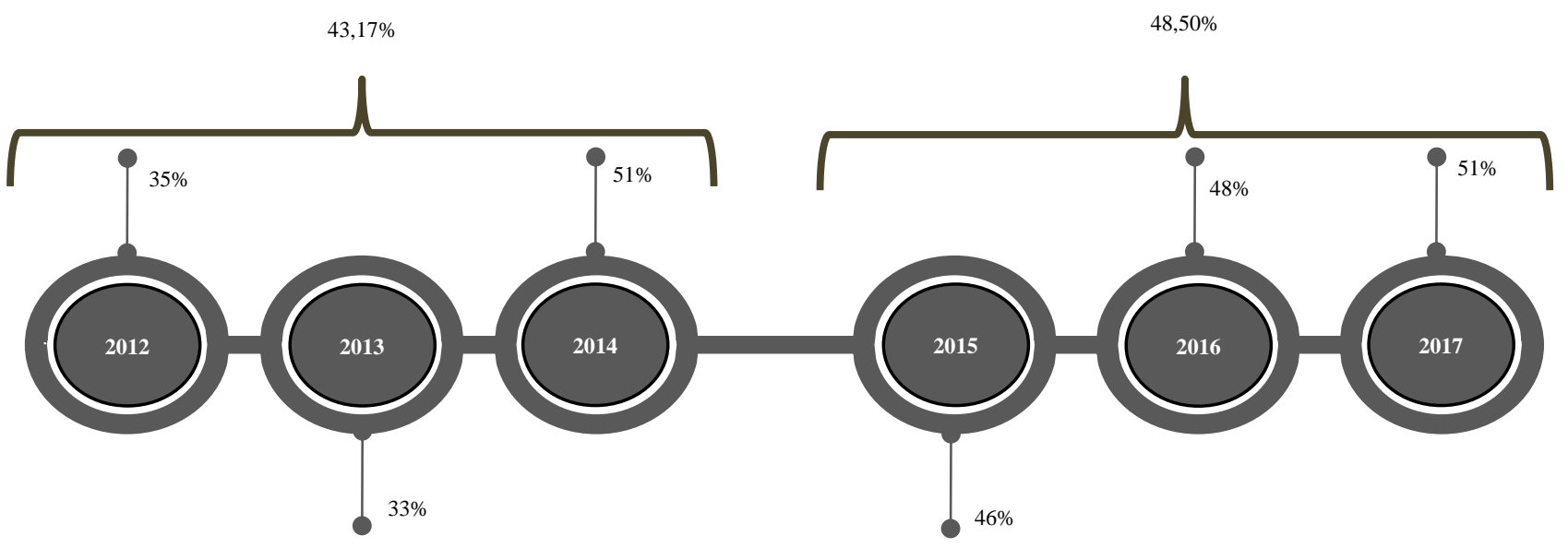

Fonte: Elaboração dos autores (2020) a partir de FNDE (2020).

As Leis Federais n. 11.326/2006 e n. 11.947/2009 e o Decreto n. 8.473/2015 regulamentam o percentual mínimo de aplicação de recursos na aquisição de alimentos da agricultura familiar para a alimentação escolar e para qualquer instituição pública que forneça refeições, em nível municipal, estadual e federal. Em Santa Catarina, este mercado para a agricultura familiar pode superar R\$ 250 milhões em um ano. No Brasil, em 2016, dos R 3,88 bilhões repassados pelo FNDE ao PNAE, 22,12\% foram aplicados na compra da agricultura familiar e, em 2017, o valor destinado foi de $\mathrm{R} \$ 3,91$ bilhões, sendo $21,61 \%$ deste valor investido na agricultura familiar. Neste sentido, revela-se que o valor mínimo previsto em Lei não foi aplicado, implicando perda parcial de um mercado que já é garantido por lei para a agricultura familiar, o que decorre, em muitos casos, de fatores econômicos e organizacionais do setor (SANTA CATARINA, 2019). Entretanto, pondera-se que podem existir fatores relacionados ao setor público impactando nesta aquisição e 
que estas perdas podem ser entendidas, em alguma medida, como responsabilidade compartilhada entre a agricultura familiar e o setor público.

Quanto ao desempenho do estado na compra de alimentos da agricultura familiar para o PNAE, Santa Catarina utilizou, em 2016, 36,46\% dos recursos repassados pelo FNDE. Já em 2017, a utilização foi de 36,03\% do recurso, demostrando que o estado está acima da média nacional, que foi de 22,12\% em 2016 e 21,61 \% em 2017 (SANTA CATARINA, 2019). Apesar de Santa Catarina ter ficado em terceiro lugar entre os estados na aplicação de recursos para compras da agricultura familiar (SANTA CATARINA, 2019), pondera-se que ainda existe expressivo potencial para ser explorado e relevante recurso que pode ser revertido para o desenvolvimento da agricultura familiar e, consequentemente, para a oferta de alimentos mais saudáveis para o público atendido, especialmente no âmbito do PNAE.

Neste ponto, estudos têm indicado possíveis motivos para o não atendimento ao percentual mínimo de aquisição, que também podem ser considerados como limitadores para a ampliação dos atuais percentuais de aquisição praticados pelos municípios, como a proposição de cardápios desconexos da produção da agricultura familiar, a burocracia imposta pelo processo de compra, falta de estrutura e recursos municipais, resistência dos profissionais envolvidos diretamente com a produção de alimentos como nutricionistas e cozinheiras, atuação deficiente do CAE, problemas climáticos que afetam a produção de alimentos, baixa diversidade da produção alimentar de base familiar, dificuldade com o processo de liberações sanitárias, preços dos produtos, logística, falta de confiança dos agricultores nas prefeituras, problemas políticos, insuficiência ou falta de assistência técnica (TRICHES et al., 2018).

Já estados que superam a proporção de $30 \%$ podem constituir indicativos de que há um grande número de pequenas propriedades de agricultores familiares que vivem da sua produção para autoconsumo e que, quando apoiados, comercializam o excedente de produção. Ademais, isto pode indicar que o estado possui um número de alunos, e uma demanda correspondente, passível de ser atendido com relativa facilidade por um número menor de agricultores, pois o volume de compras para atender aos 30\% pode não ser tão expressivo (SILVA et al., 2021).

Para demonstrar a abrangência deste modelo de aquisição no que diz respeito ao atendimento de escolares, registra-se, a partir de dados públicos do INEP (2017), que Santa Catarina possui 744.347 estudantes na rede básica de ensino, sendo a mesorregião do Vale do Itajaí a mais representativa, com $28,72 \%$ dos alunos matriculados, seguido pelo Norte Catarinense 
com $21,60 \%$ e pelo Oeste com $18,93 \%$. Os demais $30,75 \%$ do alunado estão divididos entre as outras três mesorregiões do estado (Figura 7).

Figura 7- Alunos matriculados na rede municipal de educação básica de Santa Catarina, por mesorregião, 2017.

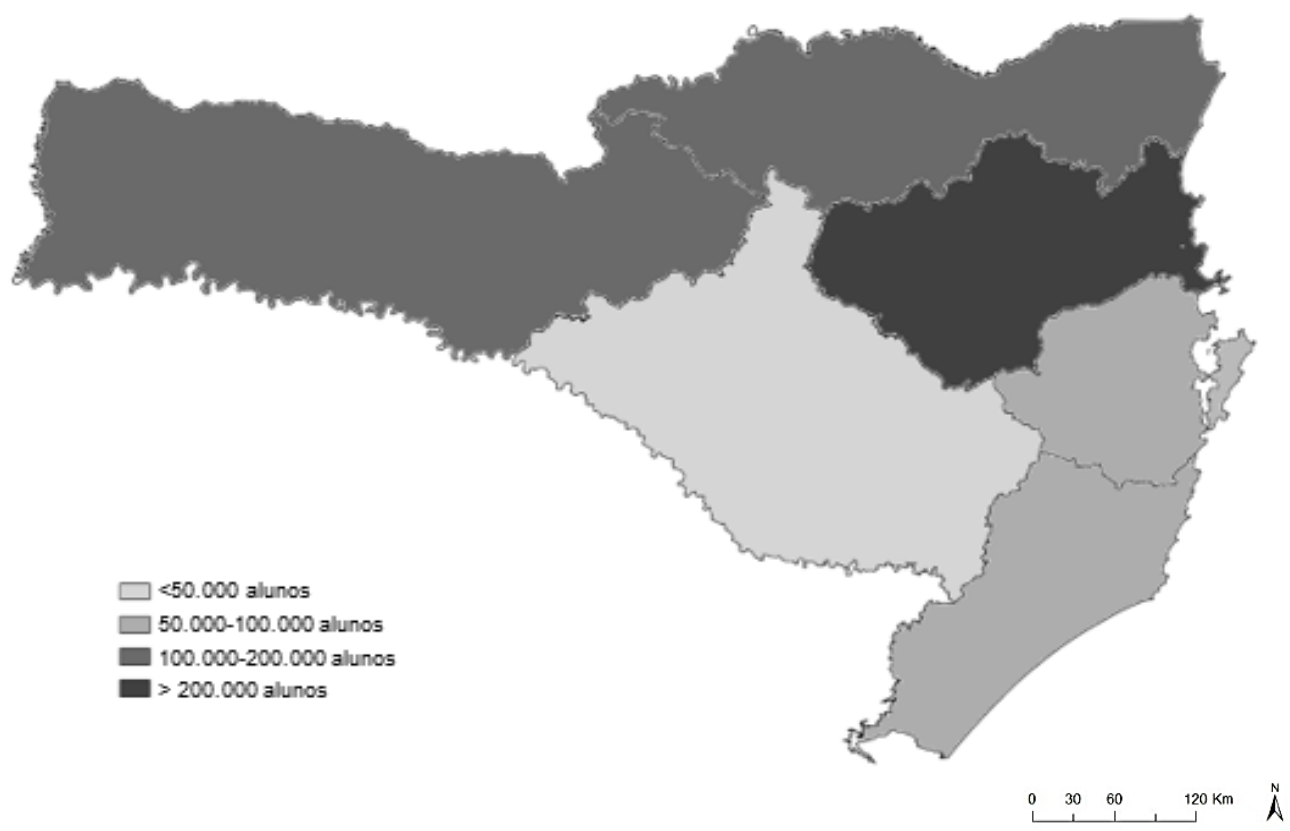

Fonte: Elaboração dos autores (2020) a partir de INEP (2017).

Dados disponibilizados pelo FNDE sobre o percentual do recurso utilizado para aquisição de alimentos da agricultura familiar para a alimentação escolar, em capitais dos estados brasileiros e no Distrito Federal, de 2011 a 2017, indicou que apenas um terço das 27 cidades avaliadas superou o mínimo recomendado, que é de 30\% (ARAUJO et al., 2019).

\section{CONSIDERAÇÕES FINAIS}

Diante do cenário apresentado, afirma-se que os municípios catarinenses, ao longo dos 10 anos da promulgação da lei que instituiu a obrigatoriedade da aquisição de alimentos da agricultura familiar para o PNAE, construiu um histórico de avanços na consolidação desta parceria intersetorial. No entanto, considerando as características do estado e a sua potencialidade de produção de alimentos, ainda é preciso avançar, quantitativamente, na participação deste modelo de aquisição de alimentos para a alimentação escolar de forma mais homogênea entre as regiões do estado. 
Diante da diversidade econômica, social, cultural e ambiental do estado, é recomendável que seja criado um plano de desenvolvimento econômico, de consolidação, qualificação para a produção e comercialização de alimentos e manutenção das atividades agrícolas de cunho familiar, considerando as singularidades e as possibilidades de produção de cada região do estado. Sugerese, nesta perspectiva, que a oferta de alimentos para as compras institucionais deva ser o foco de um plano desta natureza, haja vista que este é um mercado garantido por lei. Contudo, também é preciso ampliar possibilidades de comercialização dos produtos em cada município, pois outros canais contribuirão para a geração de renda para a família agricultora, ampliando, consequentemente, suas chances de permanência no campo, investimentos na qualificação para produção de alimentos, diversificação e ampliação da produção, o que também poderá repercutir em melhoria da qualidade e em aumento da variedade dos produtos para o PNAE.

\section{REFERÊNCIAS}

ARAUJO, Lana Raysa da Silva et al. Alimentação escolar e agricultura familiar: análise de recursos empregados na compra de alimentos. Cadernos de Saúde Pública, Rio de Janeiro, v.35, n. 11, p. e00004819, out. 2019.

ASSIS, Thiago Rodrigo de Paula; FRANÇA, André Guerra de Melo; COELHO, Amanda de Melo. Agricultura familiar e alimentação escolar: desafios para o acesso aos mercados institucionais em três municípios mineiros. Revista Economia e Sociologia Rural, Brasília, v. 45, n. 4 , p. 577-593, nov. 2019.

BACCARIN, José Giacomo et al. Indicadores de avaliação das compras da agricultura familiar para alimentação escolar no Panará, Santa Catarina e São Paulo. Revista de economia e sociologia rural, Brasília, v. 55, n. 1, p. 103-122, jan/mar. 2017.

BRASIL. Casa Civil. Lei n. 12.527, de 18 de novembro de 2011. Regula o acesso a informações. Diário Oficial da União. 18 nov. 2011. Seção 1, p.1.

BRASIL. Casa Civil. Lei n. 11.326, de 24 de julho de 2006. Estabelece as diretrizes para a formulação da Política Nacional da Agricultura Familiar e Empreendimentos Familiares Rurais. Diário Oficial da União. 25 jul. 2006a.

BRASIL. Decreto n. 9.064 de 31 de maio de 2017. Dispõe sobre a Unidade Familiar de Produção Agrária, institui o Cadastro Nacional da agricultura Familiar e regulamenta Lei n. 11.326, de 24 de julho de 2006, que estabelece as diretrizes para a formulação da Política Nacional da Agricultura Familiar e empreendimentos familiares rurais. Diário Oficial da União, Brasília, DF, 31 de ago.2017a. 
BRASIL. Ministério da Educação. Fundo Nacional de Desenvolvimento da Educação-FNDE. Lei n. 11.947, de16 de junho de 2009. Dispõe sobre o atendimento da Alimentação escolar e do Programa Dinheiro Direto na Escola. Diário Oficial da União. 17 jun. 2009a. Seção 1, p. 2.

BRASIL. Ministério da Educação. Fundo Nacional de Desenvolvimento da Educação-FNDE. Manual de apoio para as atividades técnicas do Nutricionista no âmbito do PNAE. Brasília: Ministério da Educação, 2017b. Disponível em: https://www.fnde.gov.br/programas/pnae/pnaearea-para-gestores/pnae-manuais-cartilhas/item/10493-manual-de-apoio-para-as-atividadest\%C3\%A9cnicas-do-nutricionista-no-mbito-do-pnae. Acesso em: 10 de fev. 2018.

BRASIL. Ministério da Educação. Fundo Nacional de Desenvolvimento da Educação-FNDE. Ministério do Desenvolvimento Agrário. O encontro da agricultura Familiar com a alimentação escolar. Brasília: Ministério da Educação, 2014. Disponível em: https://www.fnde.gov.br/programas/pnae/pnae-area-para-gestores/pnae-manuaiscartilhas?start=10. Acesso em: 30 de set. 2017.

BRASIL. Ministério da Saúde. Portaria Interministerial n.1010 de 08 de maior de 2006. Institui as diretrizes para a Promoção da Alimentação Saudável nas Escolas de educação infantil, fundamental e nível médio das redes públicas e privadas, em âmbito nacional. Diário Oficial da União. 08 maio. 2006b.

BRASIL. Ministério do Desenvolvimento Social- MDS. Secretaria Nacional de Segurança Alimentar e Nutricional - SESAN. Compras institucionais para Promoção da Alimentação Adequada e Saudável. Ministério do Desenvolvimento Social- MDS. Brasília. 2018. Disponível em: https://www.cfn.org.br/wp-content/uploads/2018/08/CADERNO_CI_semmarca.pdf.Acesso em: 30 de set. 2020.

BRASIL. Ministérios da Educação. Fundo Nacional de Desenvolvimento da Educação (FNDE). Resolução n ${ }^{0}$ 38, de 16 de julho de 2009. Dispõe sobre o atendimento da alimentação escolar aos alunos da educação básica no Programa Nacional de Alimentação Escolar - PNAE. Diário Oficial da União, 16 jun 2009b.

BRASIL. Ministérios da Educação. Fundo Nacional de Desenvolvimento da Educação (FNDE). Resolução n. 26, de 17 de junho de 2013a. Dispõe sobre o atendimento da alimentação escolar aos alunos da educação básica no âmbito do Programa Nacional de Alimentação Escolar - PNAE. Diário Oficial da União. 18 jun. 2013b. Seção 1, p. 7.

BRASIL. Ministérios da Educação. Fundo Nacional de Desenvolvimento da Educação (FNDE). Cartilha nacional da alimentação escolar. Ministério da Educação. Fundo Nacional de Desenvolvimento da Educação. Brasília: Ministério da Educação, 2015. Disponível em: http://www.fnde.gov.br/programas/pnae/pnae-area-para-gestores/pnae-manuaiscartilhas?limitstart=0. Acesso em: 30 de set. 2017.

BRASIL. Ministérios da Educação. Fundo Nacional de Desenvolvimento da Educação (FNDE). Resolução $n^{0}$ 6, de 08 de maio de 2020. Dispõe sobre o atendimento da alimentação escolar aos alunos da educação básica no âmbito do Programa Nacional de Alimentação Escolar - PNAE. Diário Oficial da União. 12 maio 2020. 
BRASIL. Programa das Nações Unidas para o Desenvolvimento-PNUD. Atlas do desenvolvimento humano no Brasil. Perfil de sua localidade. [2013a]. Disponível em: http://atlasbrasil.org.br/2013/. Acesso em: 15 ago. 2017.

BUNDY, Donald et al. Rethinking school feeding: social safety nets, child development, and the education sector. Washington: World Bank, 2009. Disponível em: https://siteresources.worldbank.org/EDUCATION/Resources/278200-1099079877269/5476641099080042112/DID_School_Feeding.pdf. Acesso em 12 de agosto de 2018.

CAMARGO, Jéssica Silva Moreira; NAVAS, Rafael. Programas institucionais de compra da agricultura familiar no município de Ribeirão grande/SP: uma análise a partir da produção e consumo. Revista Nera, São Paulo, v. 35, n.20, p. 231-245, jan/abr. 2017.

CARVALHOSA, Clarice Soares; BURLANDY, Luciene. Análise da trajetória de inclusão da agricultura familiar no programa nacional de alimentação escolar no Brasil. Revista UNIABEU, Belforde Roxo, v. 10, n. 26, p. 244-259, ago./dez. 2017.

CLARKE, Robert; GORLEY, Raymond. Primer: Getting started with v6. Plymouth routines in multivariate ecological research, 2005.

ESPEJO, Francisco; BURBANO, Carmem; GALLIANO, Elena. Home Grown School Feeding: a framework to link school feeding with local agricultural production. Rome: United Nations World Food Programme (WFP), 2009. Disponível em: http://hgsf-global.org/en/what-is-hgsf. Acesso em: 12 de ago. 2018.

FAO- Food and Agriculture Organization. Food and Agriculture Organization of the United Nations. International Year of Family Farming 2014: Master Plan. Rome. Disponível em: http://www.fao.org/3/as281e/as281e.pdf. Acesso em: 06 de dez. 2016.

FAO-Food And Agriculture Organization Of The United Nations. Alimentación escolar y las posibilidades de compra directa de la agricultura familiar. Estudio de caso en ocho países. Fortalecimiento de Programas de Alimentación Escolar en el Marco de la Iniciativa América Latina y Caribe Sin Hambre 2025. Roma; 2013. Disponível em: http://www.fao.org/3/ai3413s.pdf. Acesso em: 21 de nov. 2020.

FNDE-Fundo Nacional do Desenvolvimento da Educação. Histórico. [201-]. Disponível em: http://www.fnde.gov.br/programas/alimentacaoescolar/alimentacao-escolar-historico. Acesso em: abri. 2017.

GRISA, Catia et al. As práticas produtivas e alimentares no espaço rural do Oeste de Santa Catarina: a ação pública na busca e na crítica à modernidade. Estudos Sociedade e Agricultura, v. 28, n. 1, p. 78-108, fev/maio, 2020.

HAMMER, Oyvind; HARPER, David; RIAN, Paul. Past: Palaeonthological statistics software package for education and data analysis. Versão. 1.37. 2001.

IBGE- Instituto Brasileiro de Geografia e Estatística. Censo Agropecuário. Rio de Janeiro: IBGE, 2017. Disponível em: 
https://censoagro2017.ibge.gov.br/templates/censo_agro/resultadosagro/index.html. Acesso em: 20 de out. 2018.

IBGE- Instituto Brasileiro de Geografia e Estatística. IBGE cidades. [201-]. Disponível em: https://cidades.ibge.gov.br/. Acesso em: 11 de out. 2017.

INEP-Instituto Nacional de Estudos e Pesquisa Educacionais. Sinopses Estatísticas da Educação Básica. Brasília: INEP, 2012-2017. Disponível em: <http://portal.inep.gov.br/web/guest/sinopsesestatisticas-da-educacao-basica>. Acesso em: 26 ago. 2017.

MACHADO, Patrícia Maria de Oliveira et al. Compra de alimentos da agricultura familiar pelo Programa Nacional de Alimentação Escolar (PNAE): estudo transversal com o universo de municípios brasileiros. Revista Ciência e Saúde Coletiva, Rio de Janeiro, v. 23, n. 12, p. 4153 4164, dez. 2018.

SANTA CATARINA. Economia do Estado. [201-a]. Disponível em: https://www.sc.gov.br/conhecasc/economia. Acesso em: 15 ago. 2017.

SANTA CATARINA. EPAGRI- Empresa de Pesquisa Agropecuária e Extensão Rural de Santa Catarina. Síntese anual da agricultura SC-2018-2019. Disponível em:

http://docweb.epagri.sc.gov.br/website_cepa/publicacoes/Sintese_2018_19.pdf.

SCHWARTZMAN, Flávia et al. É preciso seguir com as compras diretas da agricultura familiar local pelo Programa Nacional de Alimentação Escolar. Cadernos de Saúde Pública, Rio de Janeiro, v. 33, n.12, p.1-2, dez. 2017.

SILVA, Cleverson Aléssio da et al. Programa Nacional de Alimentação Escolar: O Desempenho de Estados e Municípios Brasileiros na Aquisição de Alimentos da Agricultura. Revista Econômica do Nordeste, Fortaleza, v. 52, n. 2, p. 121-138, abr./jun. 202.

SZINWELSKI, Nádia Kunkel; TEO, Carla Rosane Paz Arruda. O ambiente alimentar escolar: desafios e possibilidades. In: TEO, Carla Rosane Paz Arruda; TRICHES, Rozane Márcia. (Orgs.). Alimentação escolar: construindo interfaces entre saúde, educação e desenvolvimento. Chapecó: Argos, 2016. p. 223-244.

TEO, Carla Rosane Paz Arruda et al. Agricultura familiar, alimentação escolar e a geração de oportunidades sociais para o desenvolvimento: experiências catarinenses. Revista Grifos, Chapeco, v. 29, n. 49, p. 67-88, maio/ago. 2020.

TEO, Carla Rosane Paz Arruda, MOSSMANN, Márcia Pozzagnol, TAGLIETTI, Roberta Lamonatto. Desafios e mecanismos de enfrentamento na relação entre Agricultura Familiar e Alimentação Escolar. Grifos, Chapecó, v. 26, n. 43, p. 34-63, jul./dez. 2017.

TRICHES, Rosane Marcia et al. Dificuldades e recursos de superação mobilizados por atores sociais na aquisição de produtos da agricultura familiar para a alimentação escolar nos estados de São Paulo, Paraná, Santa Catarina e Rio Grande do Sul. In: CASSARINO, J. P. (Org).

Abastecimento alimentar e mercados institucionais. Chapecó: Editora da UFFS. 2018. 322 p. 
TRICHES, Rosane Marcia. Repensando o mercado da alimentação escolar: novas institucionalidades para o desenvolvimento rural. In: GRISA, Catia; SCHNEIDER, Sergio (Orgs.). Políticas públicas de desenvolvimento rural no Brasil. Porto Alegre: Editora da UFRGS, 2015. p. 181-200. 